\title{
Increasing productivity in irrigated agriculture: Agronomic constraints and hydrological realities
}

Chris Perry $^{\mathrm{a}}$, Pasquale Steduto ${ }^{\mathrm{b}}$, Richard. G. Allen ${ }^{\mathrm{c}}$ and Charles M. Burt ${ }^{\mathrm{d}}$

${ }^{\mathrm{a} C}$ Consultant water resources economist, 17 Storey Court, St John's Wood Road, London NW8

8QX, United Kingdom

${ }^{\mathrm{b}}$ Division of Land and Water, FAO, United Nations, viale delle Terme di Caracalla, 00153

Rome, Italy

${ }^{c}$ Departments of Civil Engineering and Biological and Agricultural Engineering, University of Idaho, Kimberly, ID, USA

${ }^{\mathrm{d}}$ Irrigation Training and Research Center, BioResource and Agricultural Engineering

Department, California Polytechnic State University, San Luis Obispo, CA, USA 


\begin{abstract}
Irrigation is widely criticised as a profligate and wasteful user of water, especially in watershort areas. Improvements to irrigation management are proposed as a way of increasing agricultural production and reducing the demand for water. The terminology for this debate is often flawed, failing to clarify the actual disposition of water used in irrigation into evaporation, transpiration, and return flows that may, depending on local conditions, be recoverable. Once the various flows are properly identified, the existing literature suggests that the scope for saving consumptive use of water through advanced irrigation technologies is often limited. Further, the interactions between evaporation and transpiration, and transpiration and crop yield are, once reasonable levels of agricultural practices are in place, largely linear - so that increases in yield are directly and linearly correlated with increases in the consumption of water. Opportunities to improve the performance of irrigation systems undoubtedly exist, but are increasingly difficult to achieve, and rarely of the magnitude suggested in popular debate.
\end{abstract}

Keywords: Irrigation efficiency; Evaporation and transpiration; Water use efficiency; Irrigation technology; Productivity of water 


\section{Introduction}

Competition for scarce water resources is already widely evident—-from the Murray Darling basin in Australia to rivers of the middle East, southern Africa and the Americas, and from the aquifers of northern India, to the Maghreb and the Ogallala in the central US. Where water use is not regulated and controlled, imbalances between demand and supply are evident in falling water tables, drying estuaries, inadequate supplies to lower riparians and damaged aquatic ecosystems.

Climate change is generally expected to worsen the situation. While some areas will receive higher rainfall, most of the currently water-scarce regions will become drier and warmer. These two changes will exacerbate scarcity: reduced rainfall means less flow in rivers; higher temperatures mean increased evaporation and water consumption by natural vegetation (compounding the reduction in runoff), and higher water demand for agricultural use. So tensions between supply and demand are likely to be aggravated.

Irrigation is the dominant user of water in virtually all the situations where scarcity is significant, and demand for irrigation is likely to increase under the basic "drier and warmer" scenario outlined above. Improved irrigation management is thus often portrayed as the key issue in coping with current and future scarcity.

Irrigation has long been described as a wasteful, low value water use (Bhatia and Falkenmark, 1992). More recent examples are not difficult to find. The quotation below is from a guest column by Lester Brown, founder of the Earth Policy Institute, in The Indian Financial Express dated December 1, 2008. We quote here at some length because the article brings together a number of the issues that this paper will address:

"Water policy analysts Sandra Postel and Amy Vickers found that" surface water irrigation efficiency ranges between $25 \%$ and $40 \%$ in India, Mexico, Pakistan, the Philippines and Thailand; between $40 \%$ and 45\% in Malaysia and Morocco; and between 50\% and 60\% in Israel, Japan, and Taiwan". 
"Raising irrigation water efficiency typically means shifting from the less efficient flood or furrow system to overhead sprinklers or drip irrigation, the gold standard of irrigation efficiency. Switching from flood or furrow to low-pressure sprinkler systems reduces water use by an estimated $30 \%$, while switching to drip irrigation typically cuts water use in half. A drip system also raises yields because it provides a steady supply of water with minimal losses to evaporation".

"Any measures that raise crop yields on irrigated land also raise the productivity of irrigation water".

Often, as will be discussed in detail, terminology obscures rather than clarifies the discussion-thus Cooley et al. (2008), in a major report on water use in California, state:

In this analysis, we quantitatively estimate changes in water withdrawals and provide qualitative estimates of changes in consumptive use where possible. (p. 16)

However, the apparently vague "qualitative estimates of consumptive use" are firmly "translated" into specific volumes of water:

For example, the savings we find in these scenarios can be compared using "dam equivalents". Assuming that a dam yields 174,000 acre-feet $\left(215\right.$ million $\left.\mathrm{m}^{3}\right)$ [of "new" water, our efficiency scenarios save as much water as provided by 3-20 dams of this size. (p. 6)

Later, while detailing the most substantial anticipated saving (through better irrigation scheduling) it is noted that:

Water-use efficiency is defined here as yield divided by applied water. (p. 27, emphasis added)

The purpose of this paper is to bring together key messages from the existing, peer-reviewed science. On this basis, we will challenge the fundamental assumptions embodied in the quotations set out above. We will argue that "local" estimates of irrigation efficiency bear no necessary relationship to what is happening at the basin scale, and are consequently often misleading; that advanced irrigation techniques can sometimes result in increased water consumption; and that improving yields does not necessarily mean increased water productivity; and that these indicators should in any case not be measured in terms 
of water applied. Most importantly, we argue that impacts must be carefully assessed though the application of those proven scientific principles of hydrology, irrigation technology, energy balances, and plant physiology that actually define and constrain the options available.

The paper is in six parts. Following this introduction, the second section sets out widely reviewed, unambiguous terminology for describing water use in irrigation and other sectors. This will already highlight some existing confusion, and also provide the terminology for the subsequent sections. The third section deals with evaporation and transpiration - the critical components of water demand in situations of scarcity.

The fourth section turns to the crop production resulting from the use of more or less water in irrigated agriculture - how yield responds to water availability, how yield is affected by water stress, and how climate (temperature, humidity, etc.) affect water demand and crop production.

The fifth section considers the engineering options that affect how irrigation water is applied at project and farm level, and how these affect water use and the demand for water.

Finally, the interactions between these factors are brought together, and the conclusions summarized.

\section{Water accounting}

Water accounting has developed from two distinct perspectives - irrigation engineering and hydrology (which term we use to include hydrogeology).

Hydrology is the study of the movement, distribution, and quality of water throughout the Earth. Hydrology provides a general physical framework for understanding the flow of water, especially at large scales. The hydrological cycle comprises evaporation from land and water surfaces and transpiration from vegetation, which together move water into the atmosphere, and precipitation onto land and sea. Hydrologists usually take a basin perspective, analyzing precipitation, evaporation and transpiration, runoff to streams and rivers, recharge to aquifers and outflows to the sea. 
The irrigation engineering perspective looks more narrowly at interventions designed to utilize surface water flows or groundwater for application to crops where rainfall is inadequate to meet crop demand. Obviously not all the water diverted at the source reaches the field - there is canal seepage, evaporation from wet soil, and so on - and these considerations led to the development some 60 years ago of concepts of efficiency (Israelsen, 1950) that defined ratios between the quantity of irrigation water that meets its intended purpose and the diverted quantity as "efficiency"-for example conveyance efficiency (the ratio of water volume delivered to the fields to the water diverted into the canals) and field application efficiency (the ratio of irrigation water stored in the root zone to irrigation water applied to the field). Both the hydrological and the engineering approaches have merit: the hydrological approach is a general framework for understanding water flows, the engineering approach is essential for design and operation of irrigation systems and municipal water supply systems.

However, to understand and interpret the impacts of changes in water management, analysis must conform to the law of conservation of mass, where water is neither created nor destroyed, but only stored or transferred spatially as liquid or latently as evaporation. The use of the terminology and analytical framework of irrigation engineering is often unhelpful - at times even misleading and perverse - in the context of water scarcity at scales beyond the irrigation project itself. Concern at this issue is not novel: in 1979, the US Government completed a report, Irrigation Water Use and Management (ITF, 1979). Regarding irrigation efficiency, they stated:

“[A]ny report dealing with irrigation efficiencies must first define "efficiency" with a great deal of care. Many different and sometimes conflicting definitions have been published. It is frequently assumed that because irrigation efficiency is low, much irrigation water is wasted. This is not necessarily so". (p. 22). In other words, "losses" at the scale of an individual field or an irrigation project are not necessarily "losses" in the hydrological sense because, according to the law of conservation of mass, the "lost" water may be available for use at some other point in the basin, or from an aquifer. A simple example of this is in a monsoon climate, where excess water is available in one season (but cannot otherwise be stored) and 
water is scarce in another season. Irrigation "losses" that recharge the aquifer in the wet season will improve ground-water availability in the dry season.

This is not to advocate excessive irrigation applications in general: in arid and semi-arid climates, excess irrigation water can cause waterlogging, and, when that water evaporates, leave the soil salinized. In this case, water is wasted, and the productivity of the land is reduced.

It is thus essential to evaluate every case carefully and to 'follow the water' to determine its fate and disposition. Often, such careful analysis will not fully support simple assumptions that "using" less water is the same as "saving" water. The conclusion that improving irrigation efficiency and reducing losses might not result in increasing the availability of water for other uses has not proved easy for nonspecialists to grasp. In every other context, if we improve efficiency, we consume less: energy-efficient boilers consume less gas or electricity; fuel efficient cars consume less petrol, and so on. Utilizing the term "efficiency" in and of itself carries the implication of being "good". It is a value-laden term.

While the recognition that improved irrigation efficiency must be carefully interpreted is growing (for an excellent recent example, see Ward et al., 2008), several researchers have advocated the use of "fractions" terminology to describe the hydrologic outcome of water use ([Willardson et al., 1994], [Molden and Sakthivadivel, 1999], [Molden et al., 2001], [Jensen,_2007] and [Clemmens et al., 2008]). Following a review of these and many other papers and reports, and consultation throughout the National Committees of the International Commission on Irrigation and Drainage, Perry (2007) set out such terminology, stressing that it is suitable for unambiguous application to all types of water use, including hydro-power, domestic, industrial, environmental and irrigation. The terms are:

Water use: any deliberate application of water to a specified purpose. The term does not distinguish between uses that remove the water from further use (evaporation, transpiration, flows to saline sinks) and uses that have little quantitative impact on water availability (navigation, hydropower, most domestic uses). Water use goes to the: 
1. Consumed fraction (evaporation and transpiration) comprising:

a Beneficial consumption: Water evaporated or transpired for the intended purpose-for example evaporation from a cooling tower, transpiration from an irrigated crop.

b Non-beneficial consumption: Water evaporated or transpired for purposes other than the intended usefor example evaporation from water surfaces, unwanted riparian vegetation, wet soil.

2. Non-consumed fraction, comprising the:

a Recoverable fraction: water that can be captured and reused-for example, flows to drains that return to the river system and percolation from irrigated fields to aquifers; return flows from sewage systems. ${ }^{1}$

b Non-recoverable fraction: water that is lost to further use-for example, flows to saline groundwater sinks, deep aquifers that are not economically exploitable, or flows to the sea.

The law of conservation of mass dictates that the consumed fraction and non-consumed fraction sum to 1.0. Usage of this set of terms in describing water use and impacts of water management change has a number of benefits:

- It is entirely consistent with the science of hydrology — and the critical importance of hydrological context is obvious: canal seepage over a utilizable aquifer becomes recharge and is eventually recoverable; drainage flows into an estuary near the sea are most probably non-recoverable.

- The terminology is consistent across sectors, allowing unambiguous discussion of the hydrological impacts of alternative technologies and interventions.

- The terminology can be applied at any scale without modification.

- The terminology is "value-neutral", i.e., it is not value laden by the word "efficiency"- beneficial use is whatever society defines it to be; riparian vegetation may have no value in some areas, while constituting a valuable wetland in another. 
- Attention is directed clearly to what we want (beneficial consumption), what we do not want (nonbeneficial consumption and non-recoverable flows), and what is of secondary interest (recoverable flows).

It may seem trivial to rename these various flow components that occur during water resources management. However, the following examples are presented to illuminate the significance of the problem:

• "Efficient" domestic supply systems involve virtually no consumptive use; outflows are captured, treated and returned to the water resources system. "Efficient" irrigation systems result in substantial consumptive use, as $85 \%$ or more of the diversions go to crop evapotranspiration. When specialists in these two sectors promote improved efficiency in papers, conferences and workshops, what they are advocating will have quite different - indeed often opposite - hydrological impacts with regard to downstream availability of water. ${ }^{2}$

- The latest Intergovernmental Panel on Climate Change report on Climate Change and Water (Bates et al., 2008) mentions "water-hungry appliances such as dishwashers, washing machines, lawn sprinklers, etc."-failing to distinguish between non-consumptive uses (dishwashers and washing machines, where virtually all the water used can be recovered, treated if necessary, and reused) and consumptive uses (lawn sprinklers), and to understand the fundamental significance of that distinction - let alone to realise, as will be described later, that a really well designed lawn sprinkler will result in higher water consumption.

- In Yemen, a World Bank project (World Bank, 2003) has claimed that millions of cubic meters of water can be "saved" through the introduction of improved irrigation technology. The claim is based entirely on reductions in water use, while no measurements were taken of water consumed with the earlier or the upgraded technology. The appraisal report indicated that the areas being upgraded are underlain by a shallow aquifer, so the question of how much of the non-consumed fraction is recoverable and is already 
being re-extracted and put to additional use is of fundamental importance to assessing the project's impact.

- The Pacific Institute (2007) quotes Egypt's annual renewable water resource as $86.8 \mathrm{~km}^{3}$ —a surprisingly high figure, given that Egypt's agreed share of the Nile is $55.5 \mathrm{~km}^{3}$, and rainfall is negligible. Meanwhile, Earthtrends (2007) reports a figure of $58 \mathrm{~km}^{3}$, with "Internal renewable resources adding an additional 1 cubic kilometer". Both sources refer to the FAO's AQUASTAT as a source of information. The source of confusion, of course, is that the higher figure is a measure of water use, and much of that use is in the form of re-use of the recoverable fraction.

Use of the terms proposed by ICID adds clarity to the analysis of water resources management: it becomes clear, for example that minimizing return flows is progressively more important as the use nears the outflow to the sea. Return flows in tidal areas such as the Thames in London, or in narrow coastal strips exploiting runoff from inland hills, often cannot be recovered for further use. In such cases, minimizing return flows (through the use of advanced irrigation technology, or low flow showers and toilets) will typically save water for productive use elsewhere.

One final addition is needed to complete the terminology for this paper, and again it is designed to clarify an area of confusion. Conventionally, "Water Use Efficiency" is defined as a productivity term—output of crop per unit of water (Jones, 2004). However, the term is so widely misused and confused with the old term of irrigation efficiency (the proportion of water used that is consumed by the crop) as to have become meaningless. Here we use the term water productivity, defined as output of crop per unit of water consumed.

\section{Transpiration and evaporation-definitions, interactions and typical}

\section{relationships}


Transpiration is the flow of water vapor from stomates of leaves that causes replacement liquid water to move from soil to roots, through stems and on to leaves. Water vapor exits through the same stomates that carbon dioxide enters. The water vapor lost by transpiration in exchange for carbon dioxide is the primary process for plant growth and development. Other nutrients are "delivered" from the soil by the water used in transpiration.

Evaporation is the direct conversion of water into water vapor when wet leaves or soil are exposed to drier air and radiant heat.

Evapotranspiration (ET) is defined as the sum of direct evaporation (E) and transpiration (T) of soil water through plant systems and into the atmosphere.

Evaporation and transpiration are the components of the hydrologic cycle where liquid water does 'disappear' from the local hydrological system in the form of vapor to return via precipitation at some other location, and some other time. Thus, and because of its generally large magnitude, ET is an important part of the hydrologic cycle, and of water balances. Understanding, evaluating and influencing ET are critical elements of basin-scale water resources management.

This process of converting liquid water to vapor consumes large amounts of energy (approximately 2.5 megaJoules per $\mathrm{kg}$ ). The environmental energy available at any location at any specific time determines the maximum rate of evaporation, and is defined by available radiation energy from the sun and to lesser degrees by heat from the air, moderated by wind speed and air humidity. These four parameters (solar radiation, air temperature, air humidity and wind speed) are the four weather parameters employed by many ET equations.

The concept of a nearly fixed energy requirement to evaporate a unit of water is the foundation of all modern ET calculation methods, for example the Penman-Monteith equation used by FAO to estimate ET from weather data (Allen et al., 1998). The FAO 'reference' ET approximates a near upper limit for ET from an extensive surface of fully watered vegetation with specified characteristics at a specific location. 
This reference ET, adjusted for crop characteristics, defines potential ET - the maximum rate of water evapotranspiration for that location and crop.

Reference evaporation rates tend to be greatest in areas of the world having the greatest hydrologic water scarcity due to the negative feedback between general water scarcity and climatic aridity; if less water is available, less actual ET takes place, humidity is decreased, and evaporative demand and reference ET increase. Conversely, if more water is available, more ET takes place, humidity is increased (i.e., aridity is reduced) and evaporative demand decreases.

Actual ET (as distinct from potential ET) is the managed outcome of irrigation of agricultural crops and an unmanaged outcome of rainfall on rainfed crops and natural vegetation. If the water supply is fully adequate to meet the demand implied by the FAO "reference" value, then actual and potential ET will be the same.

The objective of irrigation is to make sufficient soil water available to meet transpiration requirements that are dictated by the local climate, the amount of plant cover, and the stage of growth. In general, it is the fulfillment of potential rates for $\mathrm{T}$ that govern crop yield, with $\mathrm{E}$ as an incidental and often unavoidable associate. Under water deficit conditions, crops respond by first reducing canopy growth and then closing stomata, which in turn reduces $\mathrm{T}$, carbon assimilation, biomass production and harvestable yield below potential.

For a fully watered crop there is a maximum potential value for ET defined by environmental energy. Thus any increase in E must result in an offsetting decrease in $\mathrm{T}$, and reduced production per unit of consumed water.

Strategies to obtain shifts from $\mathrm{E}$ to $\mathrm{T}$ include organic and plastic surface mulching, reduction in frequency and spatial extent of surface wetting by irrigation, reduced tillage, and higher plant densities. 


\section{Engineering options: how irrigation water is applied at project and farm level, and how this affects water use, consumption, and the demand for water}

There is no simple answer to the question "what irrigation method is best?". The Irrigation and Drainage Division of the American Society of Civil Engineers (Burt et al., 1999) provides a reference that discusses the complexities.

Irrigation technology is often a farm-level choice, and it is appropriate to consider the farmer's perspective carefully in understanding options and impacts. Thereafter, as recommended in Section 3, we will wish to "follow the water" to understand the wider water implications.

Farmers invest in improved irrigation technology for a variety of reasons, including:

- Increased income: if yield tonnage, quality, or alternative, high value crops will more than adequately pay for investment, there is an incentive to improve.

- Risk aversion/food security: Farmers may shift from rainfed agriculture to irrigation to reduce the uncertainties associated with variable rainfall patterns. Similarly, farmers may shift from public, surfacedelivery systems to well water because the surface water is delivered in an inflexible and unreliable manner.

- Convenience: This is primarily seen in commercial farming. As an example, a farmer may not want to have to wake up in the middle of the night to receive project water deliveries, or he may be able to deliver fertilizers more precisely and cheaply through "fertigation" systems.

- Reduced costs: A farmer may save pumping costs if delivery losses are reduced; he may save labor by installing equipment that does not require constant field presence.

Not all of these motives are water-related - saving labor, growing higher value crops, reducing uncertainty - and these factors, together with cost, credit availability, extension advice, technical support and various other factors will influence a farmer's selection of technology. But $\mathrm{T}$ is what 
drives biomass production, and biomass production (subject to important qualifications addressed in the next section) determines how much produce the farmer will have to sell. From the farmer's perspective, in the terminology of Section $\underline{2}$ maximizing beneficial consumption $\left(\mathrm{T}_{\mathrm{act}}\right)$ is a legitimate and high priority objective.

Similarly, the farmer will generally wish to minimize all other flows (non-beneficial consumption, and flows of non-consumed water to drains and groundwater). From the farmer's perspective such flows are lost.

For example, the simplest single intervention to improve production is often improved land leveling. Ensuring that crops are not over-irrigated in low areas (resulting in percolation) or under-irrigated in high areas (resulting in below-potential yield) is a clear benefit to the farmer because it increases beneficial consumption of water and reduces flows that produce no benefit to his operations.

There are decades of experience with almost every irrigation technology that can be imagined. Nevertheless, surprises are the norm rather than the exception when first applying those technologies in a new setting. Often apparently promising technologies are simply not suitable. Although it is desirable that field irrigation improve for many reasons (environmental, crop quality, crop yield, energy consumption, etc.) it is difficult to find the most appropriate combination of sustainable "modernization" of field irrigation hardware and management for a location.

Fig. 1 illustrates the complexity involved with making simple predictions of water saving (on the field level) and yield increases. The figure shows results from a large scale study by the Irrigation Training and Research Center (ITRC) of commercial results in a modern environment with excellent flow measurement, water delivery flexibility, and availability of technical support. The study examined water 
applied and yields for processing tomato on 187 furrow-irrigated fields and 164 drip irrigated fieldswith typical field sizes of 50 ha. It is clear from comparing yields and applied water depths in the figure that it would be risky to assume that there are immediate major benefits across-the-board when drip is implemented.

\section{--- Insert Figure 1 ---}

Note too, that the measure of water use here is water applied (as preferred by Cooley et al., 2008), not water consumed: the former term usually shows improved irrigation technology in the best possible light.

In a large scale study for the California Dept. of Water Resources ([Burt et al., 2002] and [Mutziger et al., 2005]), it was determined that in general with good management and equipment, the transpiration (T) component of evapotranspiration (ET) increases somewhat under drip irrigation. This is due to decreased stress, and some transfer of environmental energy not consumed by $\mathrm{E}$ into $\mathrm{T}$ and indicates that, while $\mathrm{E}$ has an indirect impact in reducing transpirative demand, the better approach is to reduce $\mathrm{E}$ and maximize T.

However, whether the evaporation (E) component increases or decreases is highly dependent upon the irrigation method, management and specific crop. For example, with subsurface drip irrigation (a complex drip technology) the evaporation is minimized. But for many tree crops, irrigation with conventional drip irrigation increases the E component because part of the soil surface is wetted fairly frequently. The specific differences depend upon the relative frequencies of irrigation and the percentage of soil that is wet.

There are many valid reasons to improve irrigation technology. From the farmer's perspective the potential to increase the proportion of water available at the gate that ends up as crop transpiration $(\mathrm{T})$ is the most likely source of increased revenues, and savings in labor are also 
potentially significant. Several issues must be analyzed in each situation to evaluate the wider impact of increasing $\mathrm{T}$.

First, to the extent this represents a decrease in non-productive $\mathrm{E}$, this is a clear gain to the system - but savings in E are not guaranteed, and must be critically evaluated. Second, if the increased $\mathrm{T}$ is at the expense of what were previously return flows, then it is critical to understand whether these were previously beneficially consumed elsewhere. Third, regarding improvements to the distribution system, the higher proportion of diverted water that arrives at the farm gate will sometimes allow the farmer to extend his irrigated area, which almost certainly will represent an increase in overall consumption of water.

\section{Crop production-how yield responds to water availability; how yield is affected by water stress; and how climate affects water demand and crop production}

Of the water used in crop production, the beneficial consumption is represented by that fraction of water use that is transpired by the crop itself. The water consumed by transpiration is in exchange for the assimilation of carbon dioxide (through plant stomata) leading to the production of biomass (that is, the total volume of vegetative matter produced) of which usually only a part is harvested as yield (that is, the grain, fruit or vegetable that the farmers can harvest for sale or consumption).

Often, as already described, when analyzing crop production no distinction is made between beneficial (transpiration) and non-beneficial (evaporation from soils and other surfaces) consumption of water due to practical difficulties to estimate or measure them separately. Therefore, often the water consumption of the crop is reported as evapotranspiration (ET). 
To better understand how different crops, different agro-climatic environments, and different management practices may influence the relationship between crop production and water consumption, we define the water productivity of a crop (WP) as the ratio between the amount of crop produced and the amount of water consumed to obtain such production. Moreover, in defining water productivity, we need to be specific in indicating which product (biomass or yield) and which consumption (transpiration or evapotranspiration) we are referring to. Thus, we can express the water productivity of a crop (WP) as:

- Biomass $\mathrm{WP}_{(\mathrm{T})}=(\mathrm{kg}$ of biomass $) /\left(\mathrm{m}^{3}\right.$ of water transpired $)$.

- Biomass $\mathrm{WP}_{(\mathrm{ET})}=(\mathrm{kg}$ of biomass $) /\left(\mathrm{m}^{3}\right.$ of water evapotranspired $)$.

- Yield $\mathrm{WP}_{(\mathrm{T})}=(\mathrm{kg}$ of usable yield $) /\left(\mathrm{m}^{3}\right.$ of water transpired $)$

- Yield $\mathrm{WP}_{(\mathrm{ET})}=(\mathrm{kg}$ of usable yield $) /\left(\mathrm{m}^{3}\right.$ of water evapotranspired $)$.

Over time, plants have evolved optimal stomatal behavior (Cowan, 1982) in regulating the exchange of water and carbon dioxide. As a consequence a strong, relatively constant biomass water productivity is found when considered in terms of transpiration [Biomass $\mathrm{WP}_{(\mathrm{T})}$ ], occurring under the same evaporative demand of the atmosphere, the same air carbon dioxide concentration, and the same nutritional status (Steduto et al., 2007). The essentially constant (or linear) relationship between biomass and transpiration has been observed experimentally since the early 1900s and has wide agreement in the scientific literature ([Tanner and Sinclair, 1983] and [Howell, 1990]). It is important to note from the above points that while the water productivity of a plant is essentially linear for a given situation, the slope of that relationship varies from location to location and season to season.

We now consider what options are really available to improve the biomass water productivity of a field crop. As already noted, reducing the non-beneficial water consumption (evaporation from soil and foliage) can lead to water savings. In these circumstances, production can be maintained as long as $\mathrm{T}$ is maintained. To the extent that evaporation is reduced, ET will be reduced and the overall consumptive (ET) crop water productivity is increased. This is valid for both biomass and yield water productivity. 
It is also evident that climatic conditions with reduced evaporative demand $\left(\mathrm{ET}_{\mathrm{pot}}\right)$ will reduce both beneficial (T) and non-beneficial (E) consumption of water. A reduced evaporative demand from the atmosphere is usually associated with low wind, low solar radiation, lower temperature and low vapor pressure deficit in the atmosphere (i.e., high relative humidity). When the reduced evaporative demand is associated predominantly with low radiation and temperature, it is important to account for possible impacts on the biology of the crop. Crops like maize and cotton, for example, require warm climatic conditions to grow vigorously and productively. In addition, minimum thresholds of solar radiation are needed for photosynthesis.

Options available to grow crops with reduced evaporative demand are offered when it is possible to shift crop seasons, e.g., moving spring crops into winter periods. This management practice has been shown to be successful in many cases (see Soriano et al., 2004 for sunflower). Another option is offered by controlling the climate variables as it is done when using greenhouses. Evaporative demand in greenhouses is usually of the order of $60 \%$ of the evaporative demand in open fields. Similarly, higher concentration of carbon dioxide inside greenhouses can increase assimilation of certain crops. The overall result is a significant increase in water productivity. Improved crop varieties that are resistant to cold can also offer an option to grow them in climates with lower evaporative demand.

Apart from the cases indicated above, the biomass water productivity in terms of beneficial consumption (T) is extremely stable and difficult to improve for a given evaporative demand and for a given carbon dioxide concentration. So far, the variability of biomass water productivity observed between different varieties of the same species is low (around 10\% when normalized for climate) and selection of high water productivity cultivars (such as wheat) has been of practical application in very arid dryland systems. Variation in biomass $\mathrm{WP}_{(\mathrm{T})}$, for a given climate and non-limiting nutrient conditions, is observed mainly between different large crop categories species (due to difference in their photosynthetic pathways) and between cereals, legumes, fiber crops and oil crops where a significant difference in biomass composition exists. 
Upper limits to productivity, under non-limiting nutrient conditions, can only be improved through genetics.

Genetic engineering that reduces susceptibility to pests and diseases has a clearly beneficial impact on water productivity, because crop loss after significant consumption of water can be much reduced.

Similarly, drought tolerance (that is, capacity of the plant to survive severe water stress and continue to maturity) also increases production from scarce and unreliable rainfall. However, there is very limited evidence to date of improvements in the fundamental relationship between transpiration and biomass, $\mathrm{WP}_{(\mathrm{T})}$.

Fig. 2 summarizes the relationship between biomass and water consumption (E or ET). Changes to biomass water productivity (Biomass WP) are indicated by changes in the slope of the relationship. All cases presented assume no pest or disease occurrence. In each case, the initial Biomass WP is the same, represented by line A.

\section{--- Insert Figure 2 ---}

Fig. 2(a) shows three specific cases:

- The basic conceptual relationship for a given crop under non-limiting nutrient conditions (A) in a specific climate. For a given transpiration (T1) a corresponding biomass production (M1) is obtained; the relationship is linear, and intersects the origin.

- If nutrient status of the crop is poor, the slope of the relationship is lower $\left(\mathrm{A}^{\prime}\right)$ producing less biomass (M2) for the same amount of water transpired (T1).

- Genetically improved varieties, or crops with more efficient photosynthetic processes, may show a higher slope (B) producing more biomass (M3) for the same transpiration (T1).

Fig. 2(b) represents typical field conditions in which the total water consumption (ET1) is split into its beneficial (T1) and non-beneficial (E1) components. If mulching is introduced (to reduce evaporation from the soils) then E1 can instead contribute to crop transpiration and for the same amount of total water 
consumption (up to $\mathrm{T}=\mathrm{ET} 1$ ) a higher biomass production is obtained (up to M4). The same effect is produced when a crop grows vigorously in the early stages, and the leaf canopy reduces the exposure of the soil to sunlight.

Fig. 2(c) shows the case of a crop having a deeper root growth that captures more water from the soil profile — either by reducing deep percolation or utilising residual moisture from antecendent rainfall or irrigation. The Biomass WP is not changed but a higher transpiration (T2) leads to a higher biomass production (M5), i.e., a higher production commensurate with a higher water consumption.

Fig. 2(d) shows the case of a crop that can be grown in areas, or seasons, having (i) higher atmospheric evaporative demand $\left(\mathrm{A}^{\prime \prime}\right)$, or (ii) lower atmospheric evaporative demand $\left(\mathrm{A}^{\prime \prime \prime}\right)$. In these cases, the biomass water productivity is lowered or increased due to the climatic conditions, and not to the crop characteristics and status. When the differences in climate are accounted for (e.g., climatic normalization to the reference evapotranspiration ETo, as illustrated in Steduto et al., 2007) slopes will then represent the Biomass WP specific to the crop and its nutritional status.

The key conclusion that can be drawn from the illustration of the cases in Fig. 2 is that the increase in productivity per unit area, or a water saving for the same productivity, can be derived by:

(i) increasing water productivity (i.e., higher slope of the biomass vs. transpiration relationship);

(ii) diverting the non-beneficial consumption (E) into beneficial consumption (T);

(iii) capturing more water available in the soil.

To increase the Biomass WP, options include selection of crop varieties that are well adapted to the local environmental conditions; maintaining a non-limiting nutritional status of the crop; and, to the extent possible, to grow the crop in seasons and/or areas with lower atmospheric evaporative demand.

To divert $\mathrm{E}$ into crop $\mathrm{T}$, some of the options are to use mulching opportunities, weed control, early canopy cover of the ground (e.g., early vigor type of varieties). To capture more water from the soil, options include the use of varieties with deeper rooting system and soil moisture control practices. 
Crops that withstand disease and pest attacks effectively increase the productivity of water by reducing crop failure and related unproductive water consumption up to the point of failure. Similarly, crops that tolerate drought, and recover to produce some yield also increase production per unit of water consumed. But changing the fundamental relationships between transpiration and biomass production have not yet shown significant progress.

When moving from biomass to yield water productivity, some additional considerations are needed to understand the options available for improvement. For those crops where the harvestable part of the biomass is represented by grains, fruits, or tubers, the variability in yield water productivity is quite high, even if referenced to transpiration only [Yield $\left.\mathrm{WP}_{(\mathrm{T})}\right]$, because of the variability in harvest index (HI), i.e., the proportion of biomass allocated to the reproductive organs, which varies among species.

Increasing the HI was a major strategy of the Green Revolution, when grain varieties with short stems and far more biomass concentrated in the grain were bred. However, the free ride provided by increasing HI may be ending. "Since about 1980, only minor increases in the harvest index have been achieved... it appears unlikely that further major yield increases in cereals can result from further major increases in HI.” (Sinclair and Gardner, 1998.) This conclusion is confirmed in Zwart and Bastiaanssen (2004), whose data show that crop water productivity for wheat, rice, and maize has not changed appreciably in twentyfive years.

While water stress has very limited impact on biomass $\mathrm{WP}_{(\mathrm{T})}$, it may have a large impact on yield (e.g., by reducing the number of reproductive organs). In simple terms, a crop subjected to water stress at critical times may have a considerably lower harvestable yield than a crop subjected to the same total stress (expressed as a percentage of seasonal potential demand) but at less critical periods. ${ }^{3}$ Other crops (e.g., processing tomatoes, wine grapes) must be stressed at specific growth stages to obtain the required fruit quality.

Regulated deficit irrigation (RDI) consists of reducing water deliveries when yield is relatively insensitive to stress, while ensuring full deliveries at critical periods. While undoubtedly an area for improved 
management and additional research, it is important to note that the level of management required is high, and that the risk of damaging the crop by accidental over-stressing is significant. Fereres and Soriano (2007) provide a comprehensive overview of the potential of RDI for various crops and situations.

Two important points emerge from their review: first, that providing limited irrigation water "forces" the crop to make maximum use of all sources of water — deeper rooting structures capture any residual moisture from antecedent rainfall or irrigation events, and keeping the soil relatively dry ensures that rainfall during the growing season is more likely to infiltrate into the root zone. Where such water would otherwise evaporate, this is a production gain based on increased consumption of water, not a shift in the $\mathrm{WP}_{(\mathrm{T})}$ relationship (as set out above in Fig. 2(b)).

Second, to the extent that irrigation water can be restricted while the crop yield is less sensitive to stress, and fully ensured during periods of maximum sensitivity, minor increases $\left(10 \%\right.$ or so) in $\mathrm{WP}_{(\mathrm{T})}$ can be achieved but this requires very precise control and timing of irrigation.

Although tree and fruit crops have a much more complex production process than field crops, the fundamental relationship with consumptive water use are similar. Again, however, reference to the literature (for example, Goldhamer et al., 2006) serves to demonstrate that very high management levels are required to achieve modest gains in water productivity.

\section{Conclusions}

The formulation of much of the popular criticism of irrigation is simplistic and misleading. Clear terminology - distinguishing between consumptive and non-consumptive uses, beneficial and nonbeneficial consumption, and identifying the extent to which water that is not consumed can be recovered for productive use elsewhere - is fundamental to rational analysis of the performance of irrigation systems and the scope for improvement. 
Water demand in an irrigated area depends on the climate, and the crops being grown. Those areas of the world with most limited water resources tend to be those with highest water demand. Potential demand is determined by the energy balance between the incoming radiation from the sun and the energy consumed in converting liquid water into water vapor. The balance is achieved through a combination of transpiration through the crop and evaporation from wet surfaces. Transpiration is beneficial in the sense of contributing to the formation of biomass. It is therefore desirable to maximize the transpiration component and minimize evaporation.

Improved irrigation management and appropriate technology offer scope to achieve this, though both are required for success. Poorly managed "hi-tech" systems can be as wasteful and unproductive as poorly managed traditional systems. Furthermore, careful analysis, in the terminology proposed, will often reveal that nominal "savings" in terms of water applied overstate actual reductions in consumption. Indeed, better irrigation tends to increase transpiration and studies indicate that evaporation in reasonably well managed systems is generally rather low, so that offsetting savings from this source are often insignificant. This is not to deny the many reasons that farmers opt for and benefit from improved irrigation systems - increased income from higher value crops, convenience, labor saving, lower pumping costs, etc. Real water savings are possible, but generally limited.

In assessing how productively water is used it is necessary to distinguish between biomass (the total production of vegetative matter) and yield (the production of grain, fruit, or tuber). The relationship between biomass and transpiration is essentially linear for a given crop and climate-provided nutrients are adequate. Increasing the biomass productivity of water can be achieved through improving nutrient status, growing the crop during a cooler, more humid season, or through genetic improvements.

Yield, on the other hand, can be influenced by ensuring that water is not restricted during critical growth stages, while curtailing supply at other times. Again, careful accounting must be applied, but productivity gains much in excess of $10 \%$ seem unlikely, and the level of management required is high. 
Plant breeding has delivered substantial productivity gains over recent decades — increasing the proportion of biomass going to grain, reducing the growing period, and breeding crops that tolerate lower temperatures. Genetic modification offers further promises - certainly in terms of reducing the impact of diseases and pests, possibly in terms of increased tolerance of drought - but to date the fundamental relationship between transpiration and biomass has not been changed.

Researchers will continue to identify new opportunities and approaches to improve the productivity of scarce resources, and the purpose of this paper is certainly not to deny the scope for such progress-but it is also appropriate to benefit from the substantial body of existing peer-reviewed knowledge. The opportunities are often to make incremental gains through a variety of interventions, and identifying and implementing these requires careful analysis, supportive conditions, and careful monitoring for unintended consequences.

The interactions identified in this paper suggest that where agricultural management is moderately good and water is scarce, interventions in water management sometimes approaches a zero sum gamereduced "losses" in one place reduce availability elsewhere, and increases in crop production are accompanied by commensurate increases in water consumption.

Demonstrating that an intervention is not a zero sum game is certainly an appropriate test to apply to any proposed intervention. 
${ }^{1}$ The ICID paper setting out these terms addresses the issue of pollution at some length, and recommends, because the significance of any particular type or concentration of pollution depends entirely on the proposed use, that pollution should be a separate analysis.

${ }^{2}$ Both types of use reduce streamflow between offtake points and the point where return flows arrive, with possible negative impacts on fish, navigation, etc.

${ }^{3}$ Where water is abundant, the options for improving yield water productivity are offered only through genetics. However, all crops have been improved for higher harvest index through breeding and existing genetic opportunities. Further increases seem to be limited mainly to tuber and root crops, while for crops like cereals, the genetic opportunities may have been already exploited to the limit. 


\section{References}

1. Allen et al., 1998 Allen, R.G., Pereira, L.S., Raes, D., Smith, M., 1998. Crop Evapotranspiration: Guidelines for Computing Crop Water Requirements. United Nations FAO, Irrigation and Drainage Paper 56. 1998. Rome, Italy. 300 p. http://www.fao.org/docrep/X0490E/X0490E00.htm (accessed Feb. 5, 2007).

2. Bates et al., 2008 In: B.C. Bates, Z.W. Kundzewicz, S. Wu and J.P. Palutikof, Editors, Climate Change and Water. Technical Paper of the Intergovernmental Panel on Climate Change, IPCC Secretariat, Geneva (2008), p. 210.

3. Bhatia and Falkenmark, 1992 Bhatia, R., Falkenmark, M., 1992. Water resource policies and the urban poor: innovative approaches and policy imperatives. Background paper for the Working Group on Water and Sustainable Development. International Conference on Water and the Environment, Dublin.

4. Burt and O'Neill, 2007 C.M. Burt and B.P. O’Neill, Drip and furrow on processing tomato-field performance, 28th Annual Irrigation Assoc. Technical Conference San Diego, CA, Dec. 9 (2007).

5. Burt et al., 2002 Burt, C.M., Mutziger, A., Howes, D.J., Solomon, K.H., 2002. Evaporation from Irrigated Agricultural Land in California. ITRC Report R 02-001.

6. Burt et al., 1999 Burt, C.M., Clemmens, A.J., Bliesner, R.D., Merriam, J., Hardy, L.A., 1999. Selection of Irrigation Methods for Agriculture. On-Farm Irrigation Committee. Water Resources Division. ASCE. N.Y., N.Y. ISBN 0-7844-0462-3. 129 pp.

7. Clemmens et al., 2008 Clemmens, A.J., Allen, R.G., Burt, C.M., 2008. Technical concepts related to conservation of irrigation and rainwater in agricultural systems. Water Resources Research, 44, W00E03, doi:10.1029/2007WR006095.

8. Cooley et al., 2008 H. Cooley, Christian-Smith, Juliet, Gleick and H. Peter, More with Less: Agricultural Water Conservation and Efficiency in California, Pacific Institute (2008).

9. Cowan, 1982 I.R. Cowan, Encyclopedia of Plant Physiology 12B (1982), pp. 589-612. 
10. Earthtrends, 2007 Earthtrends, 2007.

http://earthtrends.wri.org/searchable_db/index.php?step1/4countries\&cID $\% 5 B \%$

5D1/455\&theme1/42\&variable_ID1/4693\&action1/4select_years, accessed 1 May 2007.

11. Fereres and Soriano, 2007 Fereres, Elias, Soriano, María Auxiliadora, 2007. Deficit irrigation for reducing agricultural water use. Journal of Experimental Botany. 58(2), 147-159. http://jxb.oxfordjournals.org/cgi/content/full/58/2/147 viewed December 5, 2008.

12. Goldhamer et al., 2006 D.A. Goldhamer, M. Viveros and M. Salinas, Regulated deficit irrigation in almonds: effects of variations in applied water and stress timing on yield and yield components, Irrigation Science 24 (2006), pp. 101-114.

13. Howell, 1990 T.A. Howell, Grain dry matter yield relationships for winter wheat and grain sorghumsouthern high plains, Agronomy Journal 82 (1990), pp. 914-918.

14. IFE, 2008 Indian Financial Express, 2008, http://www.financialexpress.com/news/low-prices-ofwater-and-drop-in-productivity/392609/0, viewed December 5, 2008.

15. ITF, 1979 Interagency Task Force, Irrigation Water Use and Management, US Gov't. Printing Office, Washington, DC, USA (1979) 143 pp.

16. Israelsen, 1950 O.W. Israelsen, Irrigation Principles and Practices, John Wiley and Sons, Inc., New York (1950) $471 \mathrm{pp}$.

17. Jensen, 2007 Jensen, Marvin, E., 2007. Beyond irrigation efficiency. Irrigation Science, OdI 10.1007/s00271-007-0060-5, 2007.

18. Jones, 2004 H. Jones In: M. Bacon, Editor, Water Use Efficiency in Plant Biology. Chapter 2 in Water Use Efficiency in Plant Biology, Blackwell, Oxford, UK (2004).

19. Molden and Sakthivadivel, 1999 D. Molden and R. Sakthivadivel, Water accounting to assess use and productivity of water, International Journal of Water Resources Development 15(1) (1999), pp. 55-71. 20. Molden et al., 2001 Molden, D., Sakthivadivel, R., Keller, J., 2001. Hydronomic Zones for Developing Basin Water Conservation Strategies. International Water Management Institute (IWMI) Research Report No. 56. 
21. Mutziger et al., 2005 A.J. Mutziger, C.M. Burt, D.J. Howes and R.G. Allen, Comparison of measured and modified FAO 56 modeled bare-soil evaporation, Journal of Irrigation and Drainage Engineering 131 (1) (2005), pp. 59-72.

22. Pacific Institute, 2007 Pacific Institute, 2007. http://www.worldwater.org/data.html, accessed 1 May 2007.

23. Perry, 2007 Chris Perry, Efficient irrigation; inefficient communication; flawed recommendations, Irrigation and Drainage vol. 56, Wiley Interscience (2007) pp. 367-378.

24. Sinclair and Gardner, 1998 T.R. Sinclair and F.P. Gardner, Environmental limits to plant production. Principles of ecology in plant production, CAB International (1998).

25. Soriano et al., 2004 Soriano, M, Auxiliadora, Orgaz, Francisco, Villaboso, Francisco, J., Fereres, Elias, 2004. Efficiency of water use of early plantings of sunflower. European Journal of Agronomy 21:44, 465-476, Elsevier Science.

26. Steduto et al., 2007 P. Steduto, T.C. Hsiao and E. Fereres, On the conservative behaviour of biomass water productivity, Irrigation Science 25 (2007), pp. 189-207.

27. Tanner and Sinclair, 1983 Tanner, C.B., Sinclair, T.R., 1983. Efficient water use in crop production: research or re-search? p. 1-28. In H.M. Taylor et al. Limitations to Efficient Water Use in Crop Production. Am. Soc. Agron., Madison, WI.

28. Ward et al., 2008 Ward, Frank A., Pulido-Velazquez, Manuela, 2008. Water Conservation in irrigation can increase water use, Proceedings of the National Academy of Sciences, vol. 105 no. 47, 18215-18220,www.pnas.org_cgi_doi_10.1073_pnas.0805554105.

29. Willardson et al., 1994 L.S. Willardson, R.G. Allen and H. Frederiksen, Eliminating irrigation efficiencies, USCID 13th Technical Conference, vol. 19-22 Denver, Colo., October (1994), p. 15.

30. Zwart and Bastiaanssen, 2004 S.J. Zwart and W.G.M. Bastiaanssen, Review of measured crop water productivity values for irrigated wheat, rice, cotton, and maize, Agricultural Water Management (2004). 


\section{Figures}

\section{Figure 1}

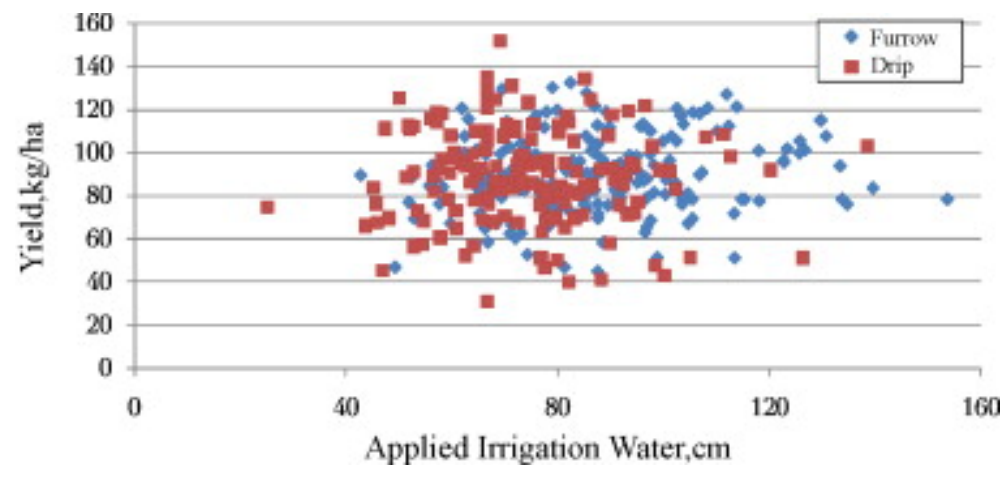

Fig. 1. Comparison of yield vs. irrigation water applied for furrow and drip irrigation of processing tomatoes in California (Burt and O’Neill, 2007). 
Figure 2
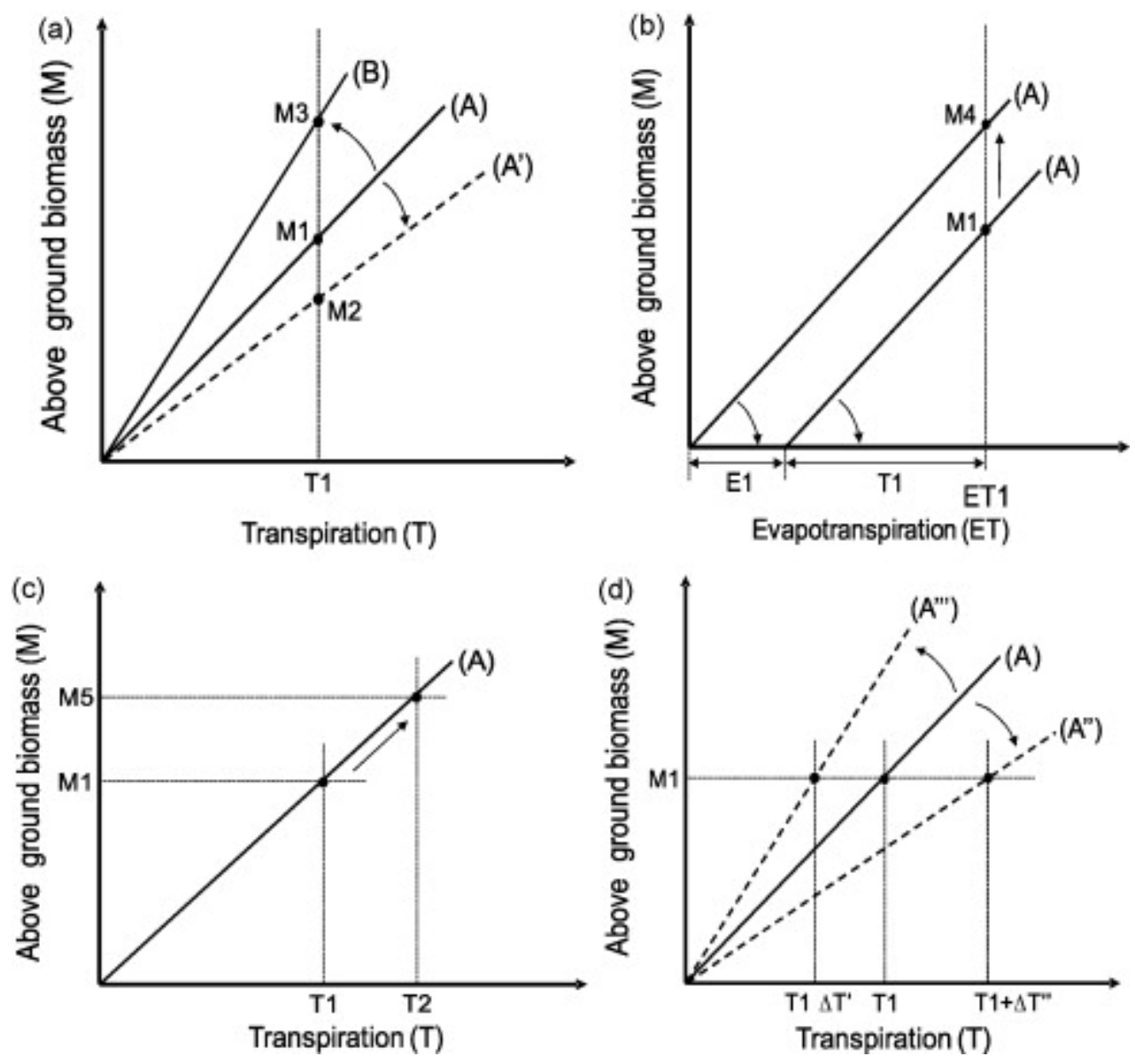

Fig. 2. Biomass vs. water consumption relationships. 